Review Article

\title{
Compartment Syndrome- Controversies and where are we Today
}

\section{Shantharam Shetty ${ }^{1}$, Ajith Kumar', Lathika Shetty ${ }^{3}$, Anbuchezhian Palanivel ${ }^{4}$}

${ }^{1}$ Pro Chancellor, Nitte University \& Professor, Dept. of Orthopedics, ${ }^{2}$ Senior Consultant, ${ }^{4}$ Senior Resident, Dept. of Orthopedics, Tejasvini Hospital, 'Professor, Dept. of Radio diagnosis, K.S. Hegde M edical Academy,

*Corresponding Author : M. Shantharam Shetty, Pro Chancellor, Nitte University \& Professor, Dept. of Orthopedics, Tejasvini Hospital, Mangalore.

Received

: 15.05.2017

Review Completed : 05.06.2017

Accepted

: 07.06 .2017

\section{Access this article online Quick Response Code

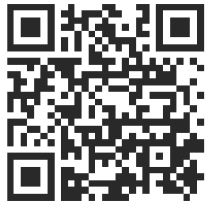

\section{Historical Review}

It was Volkmann² who described for the first time Ischemia of forearm muscles due to venous stasis resulting in irreversible contracture.

Ellis, 1958 and Seddon, 1966 contributed to this entity, especially in the treatment of lower extremity. All the retrospective reviews have advised the early recognition of the syndrome and fasciotomies of the affected limbs.

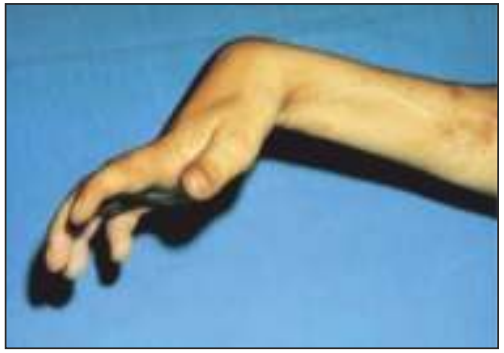

Fig. 1 : Advanced compartment syndrome with contractures

The Controversies in Compartment Syndrome today are:

1. Initial Diagnosis

2. Whether measuring compartment pressure is useful

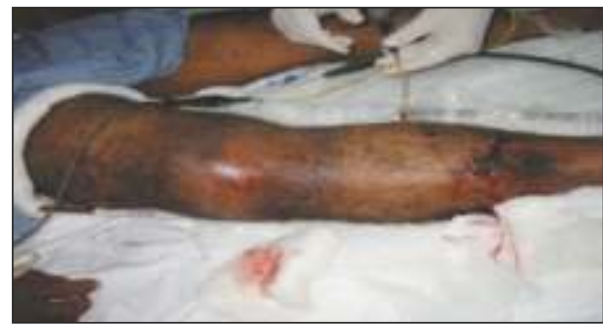

Fig. 2 : Acute compartment syndrome with blisters

and how often

3. Most important is the management and timing of fasciotomy

Early or late is a very relative term and more so for compartment syndrome in a limb since every minute counts to save a limb, prevent a deformity or an amputation or rarely even to save the life of a patient. 


\section{Common fractures causing compartment syndrome}

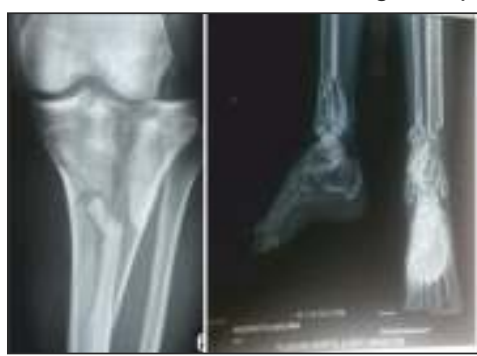

Schatzker's VI Pilon C3 (Fig. 3)

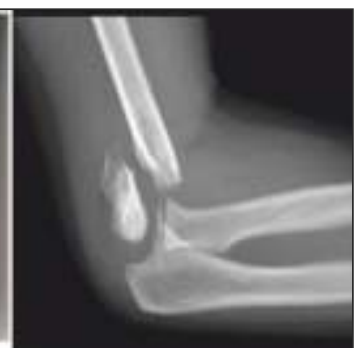

Displaced supracondylar fracture

\section{Etiology}

Compartment syndrome can be caused due to closed or openfractures ${ }^{3}$, blunt trauma, temporary vascular occlusion, plaster/dressing, closure of fascial defects, burns/electrical, exertional states, GSW, IV/A-lines, hemophiliac/ coagulopathies, intra osseous IV(infant) snake bite and arterial injury.

Of these, $80 \%$ are due to trauma usually associated with high energy injuries like Tibial Condoyle fractures, supracondylar or pilon fractures (fig. 3), mainly due to spasm of vessels or injury to the vessel or tight constriction bandages.

The disastrous sequelae of compartment syndrome are infection, ischemic contractures, crush syndrome $\&$ acute renal failure, partial / complete loss of function, amputation and even death.

\section{Controversy No. 1: Diagnosis}

The 5 P's are signs and symptoms ${ }^{4}$ of compartment syndrome - pain out of proportion- stretch pain, parasthesia, pallor, paralysis and pulselessness.The pain is like a child who is deprived of its milk. Here, the muscles are deprived of its blood supply. Unfortunately, it is missed in a polytrauma situation, hypotensive or obtunded patient. It may also be a silent compartment syndrome when there is altered consciousness, spinal or epidural, neurological deficit, sometimes even in open fractures.

Pathogenesis described by M ateson \& Krugmirev ${ }^{5}$

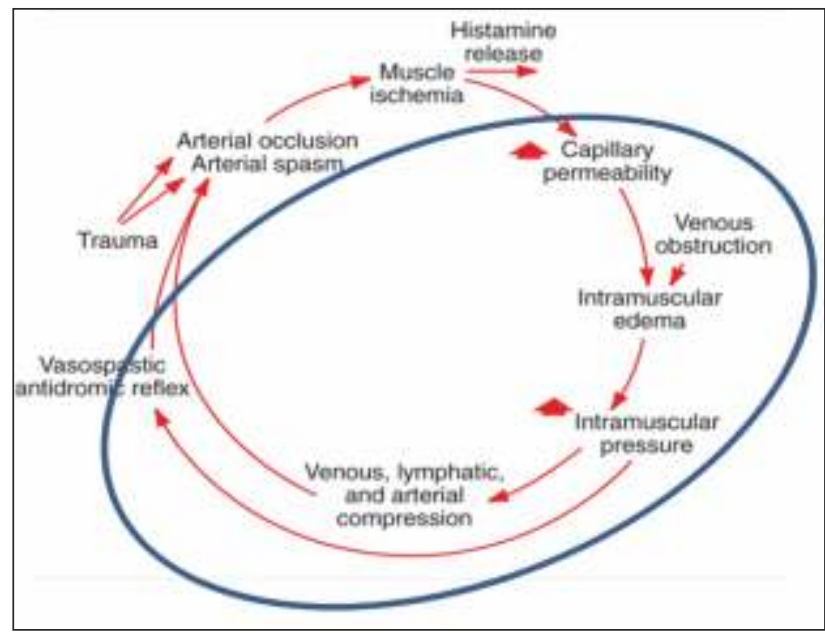

Arterial occlusion occurs at the later stages of compartment syndrome. It is important to recognize Compartment syndrome prior to this.

Skin Blisters can indicate the depth of Compartment Pressure, deep or superficial.

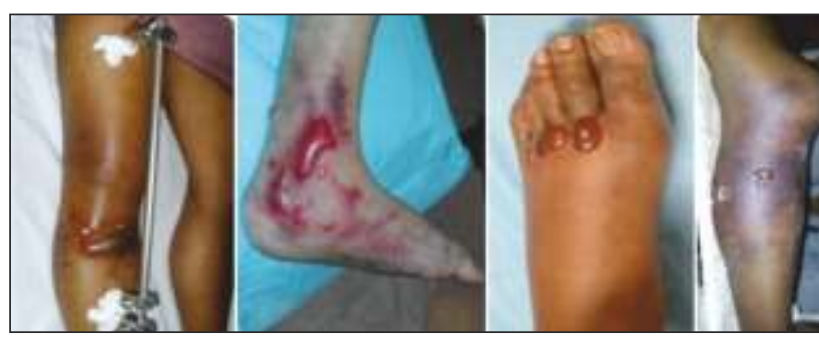

Skin blisters should also be differentiated between fluid filled or blood filled to know whether the pressure change is in the epidermis or deeper.

Skin blisters are a sign of impending compartment syndrome.

\section{If Skin Blisters are}

- Fluid filled blistersindicatecleavage within epidermis itself and will heal without scar or pigmentation.

- Blood filled blisters indicate cleavage of epidermis from dermis and heal with scar or pigmentation.

Skin blisters are a sign of impending compartment syndrome. Serial hourly pressure measurements are needed then. Plan - Wait and watch or undertake fasciotomy. 


\section{Controversy No. 2}

Should we measure the intra compartment pressure? Answer is an emphatic yes, both from the diagnostic and legal point of view.

Techniques available are:

1) Simple needle with a slit catheter.

2) whitesides technique

3) Hand held monitors

4) stryker devices

5) manometric IV pump method near infrared spectroscopy

6) Laser doplerflowmetry etc

However, these are not substitutes for clinical diagnosis.

Pressure Measurements ${ }^{6}$

Simple Needle -18 gauge is least accurate, usually gives falsely higher reading.

Slit Catheter $\&$ Side ported needle is more accurate.

\section{WHITESIDESTECHNIQUE HAND HELD MONITOR}

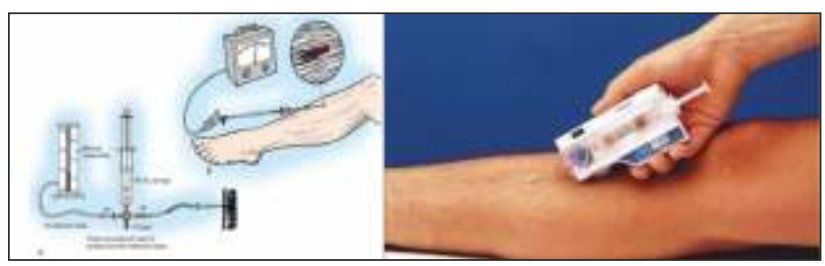

\section{M uscle Perfusion Pressure}

Compartment Pressurecan be gauged by diastolic blood pressure or intra compartmental pressure. If muscle perfusion pressure $>30 \mathrm{~mm}$ $\mathrm{Hg}$, it result in Hypoxia and anaerobic cell metabolism. Blood pressure has a direct relationship to perfusion pressure.

Measurements should be done in all the compartments; especially, in the leg, forearm and thigh. For example, all four compartments in the leg. Normal compartment pressure varies from $5-15 \mathrm{~mm}$.

\section{Pressure measurements ${ }^{7,8}$;}

\begin{tabular}{|l|l|l|}
\hline Normal tissue pressure & $0-4 \mathrm{~mm} \mathrm{Hg}$ & 8-10 with exertion \\
\hline $\begin{array}{l}\text { Absolute pressure } \\
\text { theory as described }\end{array}$ & $\begin{array}{l}30 \mathrm{~mm} \mathrm{Hg} \text { - } \\
\text { Mubarak method }\end{array}$ & $\begin{array}{l}45 \mathrm{~mm} \mathrm{Hg} \text { - } \\
\text { M atsen method }\end{array}$ \\
\hline $\begin{array}{l}\text { Pressure gradient } \\
\text { theory }\end{array}$ & $\left.\begin{array}{l}<20 \mathrm{~mm} \mathrm{Hg} \text { of } \\
\text { diastolic pressure } \\
\text { - byWhite sides } \\
\text { technique } \\
(\text { M cQueen, et al }\end{array}{ }^{9}\right)$ & \\
\hline
\end{tabular}

Uliaz A et $\left.a\right|^{10}$, reported comparing stryker, mono metric intravenous pump and white sides, latter is unreliable of the three.

Garfin, Mubarak et al $^{11}$ reported 85 - 90\% reduction of compartment pressure by taking off the plasters.

It is to be noted that all types of analgesia does not necessarily delay the clinical diagnosis ${ }^{12}$ of Acute compartment syndrome provided high degree of clinical suspicion and continuous monitoring of compartment pressure studies are followed.

\section{Controversy No. 3}

When do we undertake fasciotomy? Answer is as early as possible once the diagnosis is established ${ }^{13}$.

\begin{tabular}{|l|l|l|l|}
\hline 5 P's of compartment syndrome & Blood pressure & Intracompartment pressure & Management \\
\hline Positive & normotensive & $>30 \mathrm{~mm} \mathrm{Hg}$ & $\begin{array}{l}\text { Immediate } \\
\text { fasciotomy }\end{array}$ \\
\hline $\begin{array}{l}\text { Unequivocal findings / } \\
\text { comatose patients }\end{array}$ & hypotensive & $>20 \mathrm{mmHg}$ & $\begin{array}{l}\text { Immediate } \\
\text { fasciotomy }\end{array}$ \\
\hline
\end{tabular}




\section{Indications for Fasciotomy}

However withsignificant tissue injury or high risk patient, with $>6$ hours of total limb ischemia, with unequivocal clinical findings, pressure within 15-20 $\mathrm{mm}$ hg of diastolic blood pressure, rising tissue pressure necessitatesurgent fasciotomy.

Contraindication - Missed compartment syndrome especially after 24-48 hrs.

For the leg compartment syndrome, either a single or a double incision as shown in figure (6) is desirable.

ANTEROLATERAL SKIN INCISION POSTEROM EDIAL INCISION

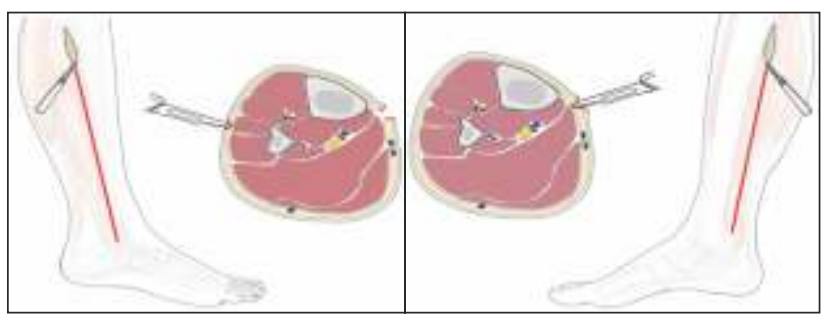

Fig. 6

Double incision technique14 is easier, faster, and safer and is recommended when all 4 compartments of leg are to be decompressed.

However, Percutaneous fasciotomy is not indicated since the skin, as long as it remains intact, acts as a limiting membrane and may sustain the compartment syndrome. All four compartments need to be released.

On opening the compartments, evaluation of muscle viability can be done by looking into color, contractility, consistency and capillary bleeding (Fig.7). In very late cases, the muscles will be darkish and no bleeding.

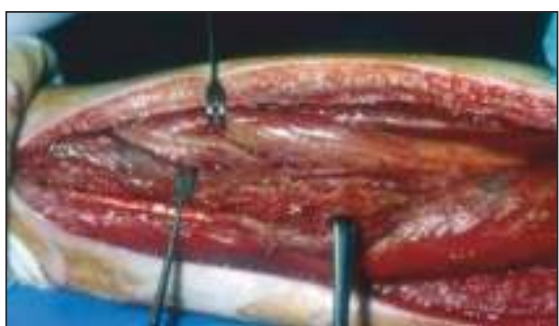

Fig 7

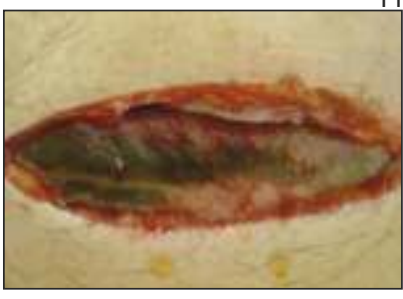

Done early

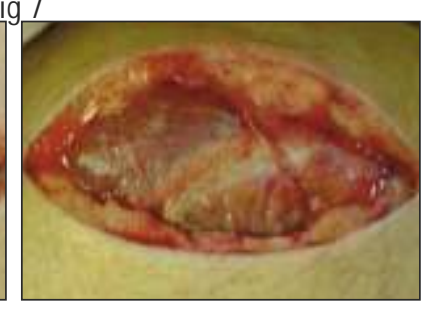

done late

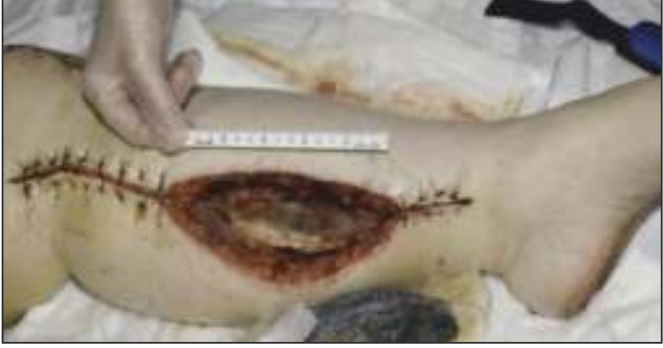

very late

\section{Compartment syndrome of thigh ${ }^{15}$}

Anterior and posterior compartment can be decompressed by single lateral incision. M edial incisions may be needed if adductor compartment is to be decompressed.

\section{In other common sites like forearm, hand, thigh and foot,} the principles are the same.

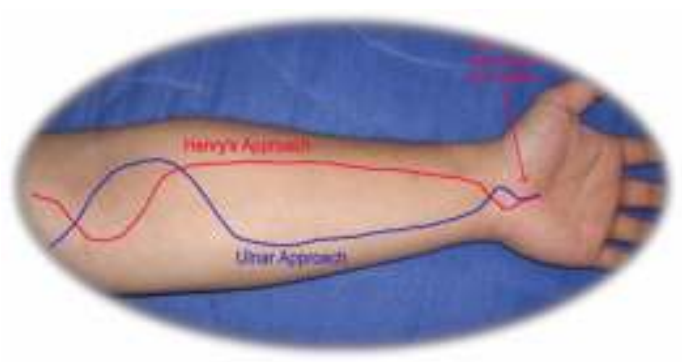

Volar approach

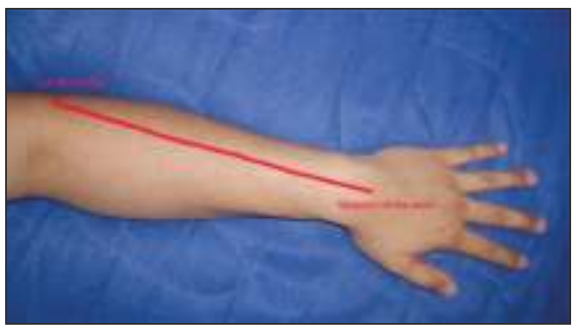

Dorsal Approach
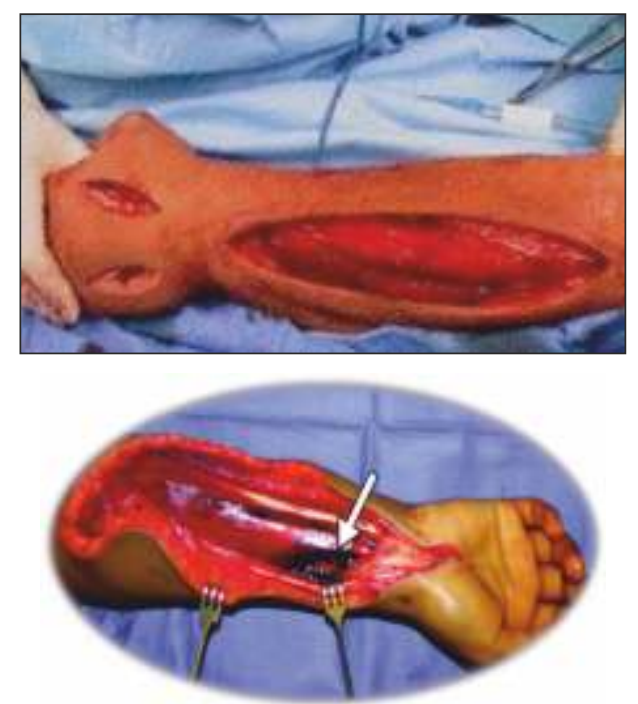

Fig. 8 


\section{Hand and Foot}

In the hand and foot, all compartments are to be released. (Fig. 9, $10 \& 11)$
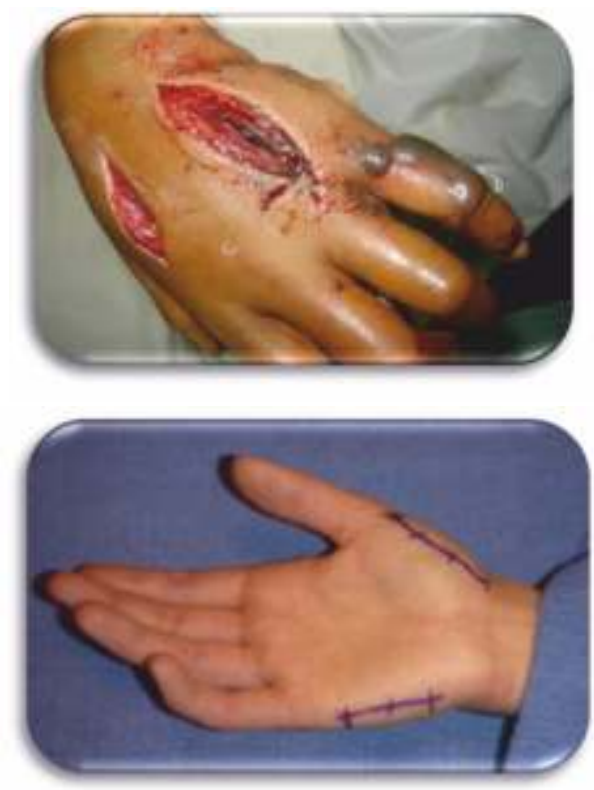

Fig. 9

Foot
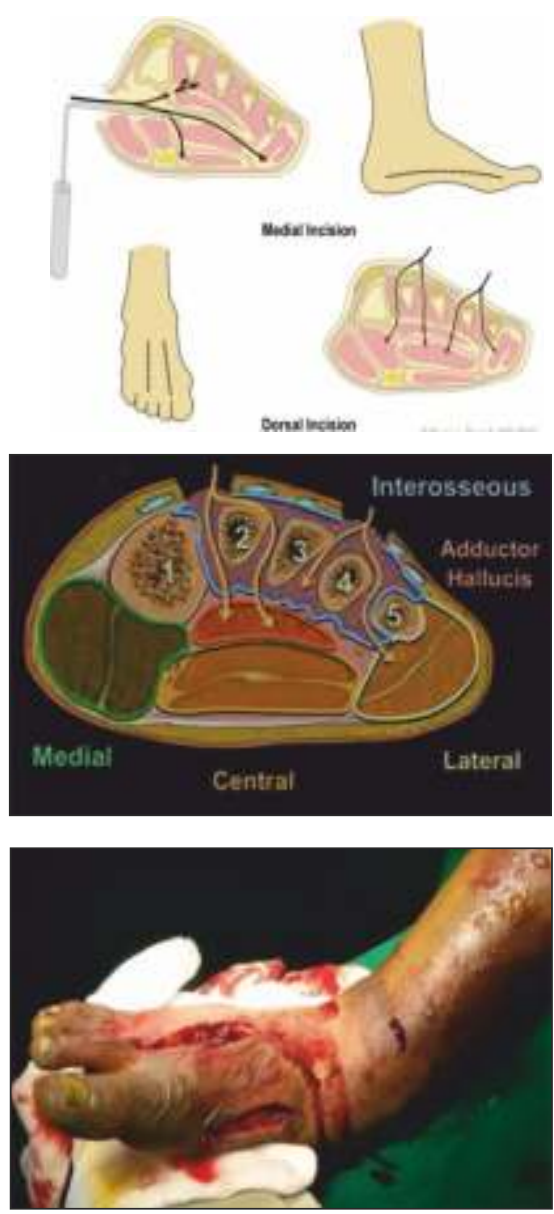

Fig. 10
Is there a role for Joint spanning external fixator - a definitive YES.

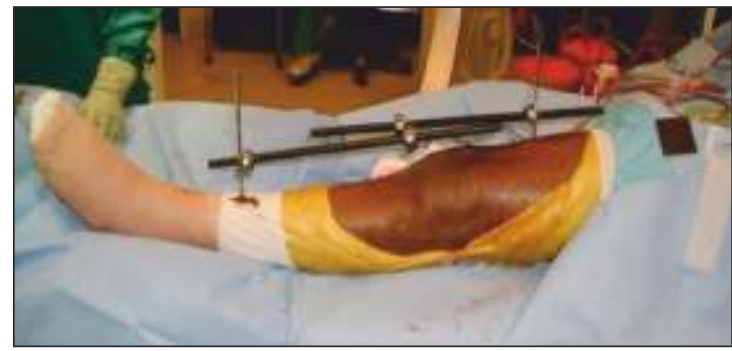

Fig. 11

Ligamentotaxis effect by the knee spanning fixators ${ }^{16}$ transiently elevates intra compartment of causing acute compartment syndrome however it's a useful tool in injuries around the knee.

\section{Fasciotomy Closure can be done in one of the following} ways:

Wound left open +VAC dressing, skin sutured 3-5 days later (when swelling subsides) $+/$ - split skin grafts and keep limb elevated.
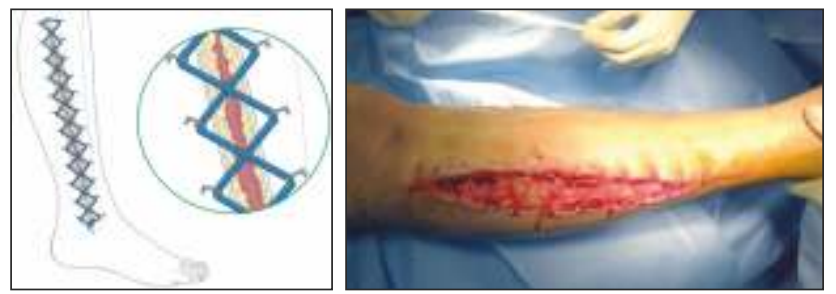

Fig. 12

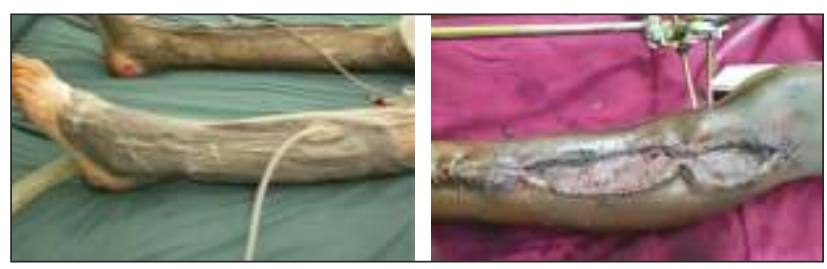

Fig 13

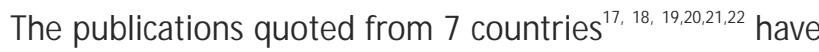
emphasized early diagnosis is the key determinant in avoiding the poor outcomes in Acute compartment syndrome.

Asfar astissue survival is concerned,

- Muscle $^{23}$

- 3-4 hours resultsreversiblechanges

- 6 hours variable damage occurs

- 8 hours irreversible changes 
- Nerve $^{24}$

- Till 1 hrconducts impulses

- 2 hrslooses conduction

- 4 hrs-neuropraxia

- 8 hrs-irreversible damage

\begin{tabular}{|l|l|}
\hline $\begin{array}{l}\text { Time to Fasciotomy from onset } \\
\text { of Compartment Syndrome }\end{array}$ & $\begin{array}{l}\text { Percentage of patients } \\
\text { regaining Normal function }\end{array}$ \\
\hline Less than 12 hours & $68 \%$ \\
\hline M ore than 12 hours & $8 \%$ \\
\hline
\end{tabular}

- If compartment syndrome has persisted for > 8-10 hrs, one should be aware and vigilant about the possibilities of acute renal failure (ARF) as noted by Kanlic EM et al in his study and prompt management of ARF should be considered.

- Skin is left intact and late reconstructive methods to be planned for sequalae ${ }^{25}$ of compartment syndrome.

Sherdan et $\mathrm{al}^{26}$ in his case series observed that routine fasciotomy has less beneficial role in delayed diagnosed cases of acute compartment syndrome.

\section{What is the role of fracture fixation in compartment} syndrome?

First, stabilized temporarily by external fixation. Internal fixation is planned once the soft tissue equilibrium is achieved.

Hak D.J et $\mathrm{al}^{27}$ in his comparative analysis found that prior fasciotomy in proximal tibial fractures does not increase the risk of deep infection after open reduction and internal fixation. Bhargava $\mathrm{R}$ et $\mathrm{al}^{28}$ in his retrospective study patients with impending compartment syndrome with proximal tibial fractures treated with single stage procedure with fasciotomy and definitive internal fixation noticed to have excellent results, however large number of patient series and multi centric studies are needed to further validate this finding.

The above mentioned studies showed that definitive internal fixation of tibial plateau fractures in the presence of open fasciotomy wounds does not seem to be associated with an increased infection risk.

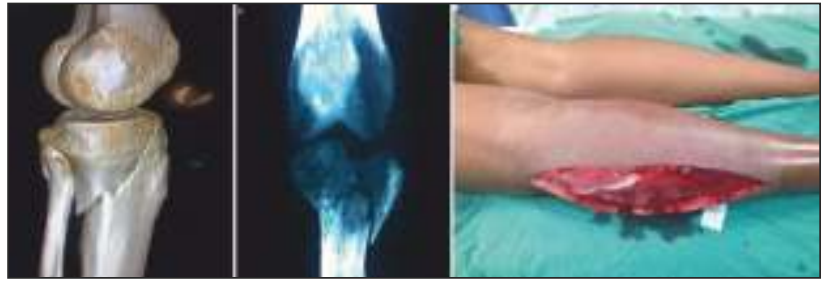

Fig. $14^{30}$

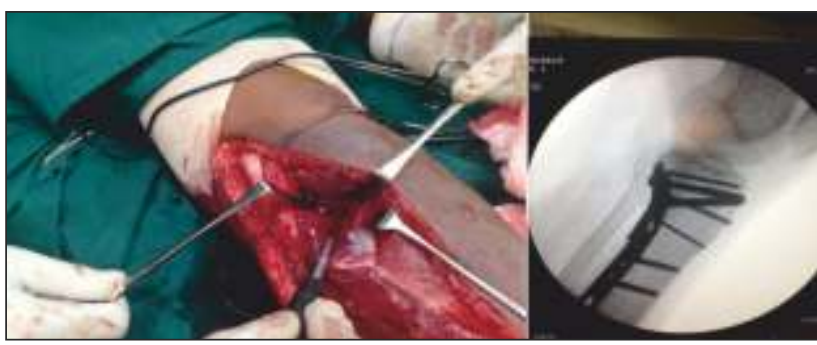

Fig. $15^{30}$

Cole et $\mathrm{al}^{29}$ in his prospective assessment of compartment pressure in legs after LISS FIXATION found out that less invasive method of fixation does not necessarily increase intra compartment pressure.

These three cases depict how one can deal with compartment syndrome either a success story or a disappointing failure.

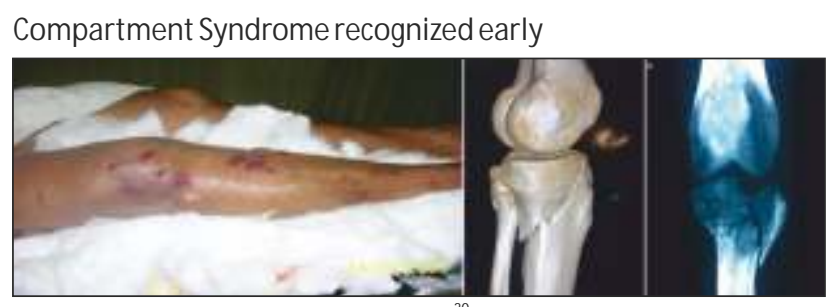

Fig. $16^{30}$

Faciotomy\& Ex-fixator and skin grafting done.
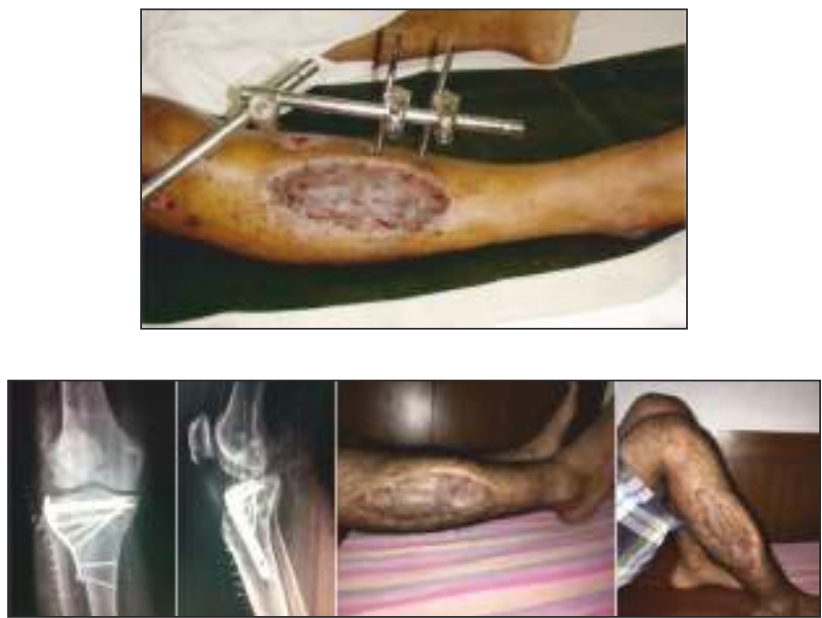

Definitive fixation

Final result 
Case - 2 : 28 years old with right knee injury

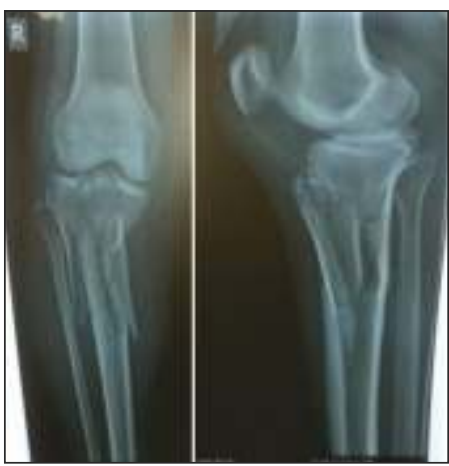

Fasciotomy done and spanning fixator applied

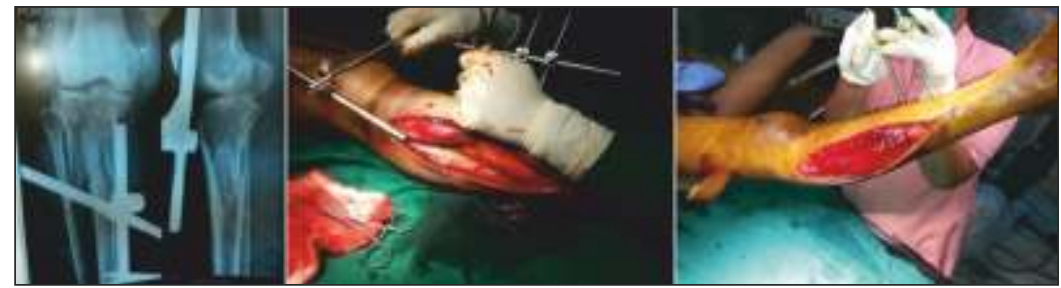

Fig. 17: Closed type VI Tibial Condyle Fractures
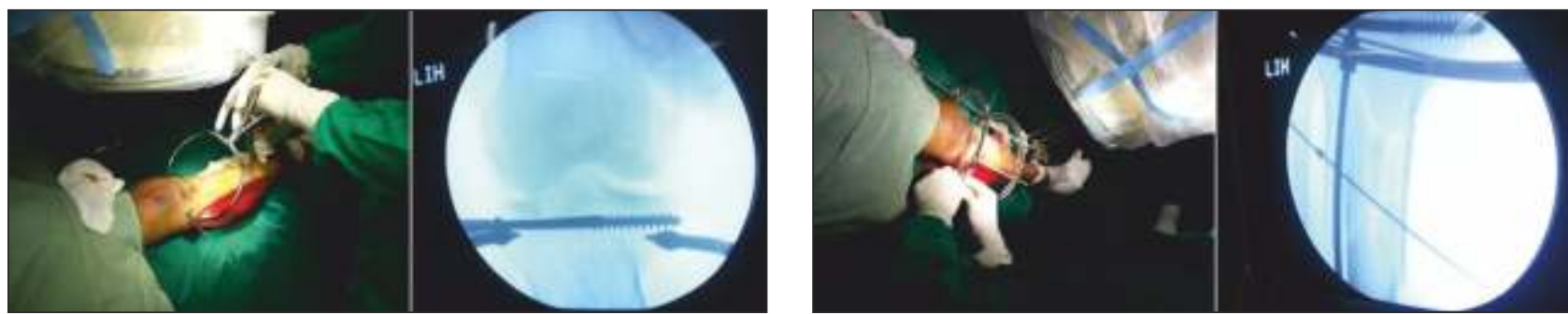

Fig. 18 : Steps of operation
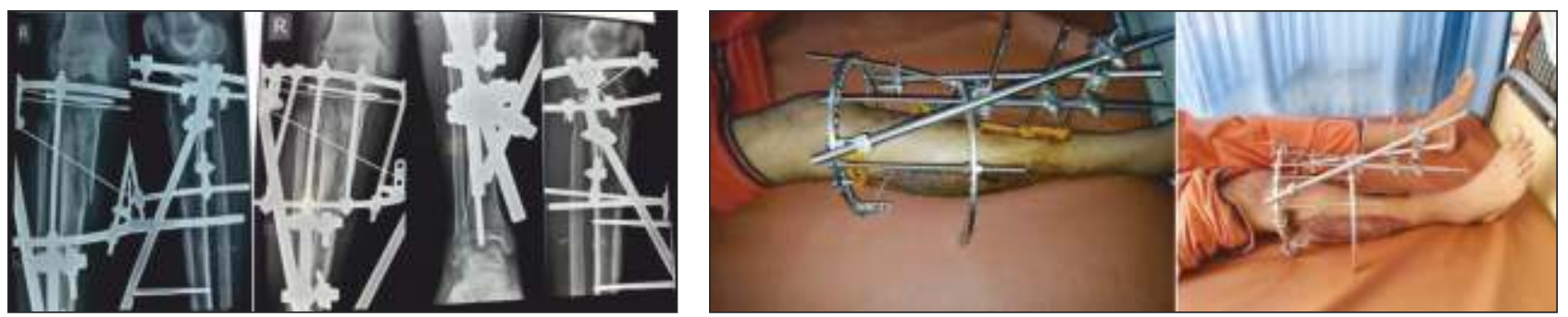

With hybrid external fixature
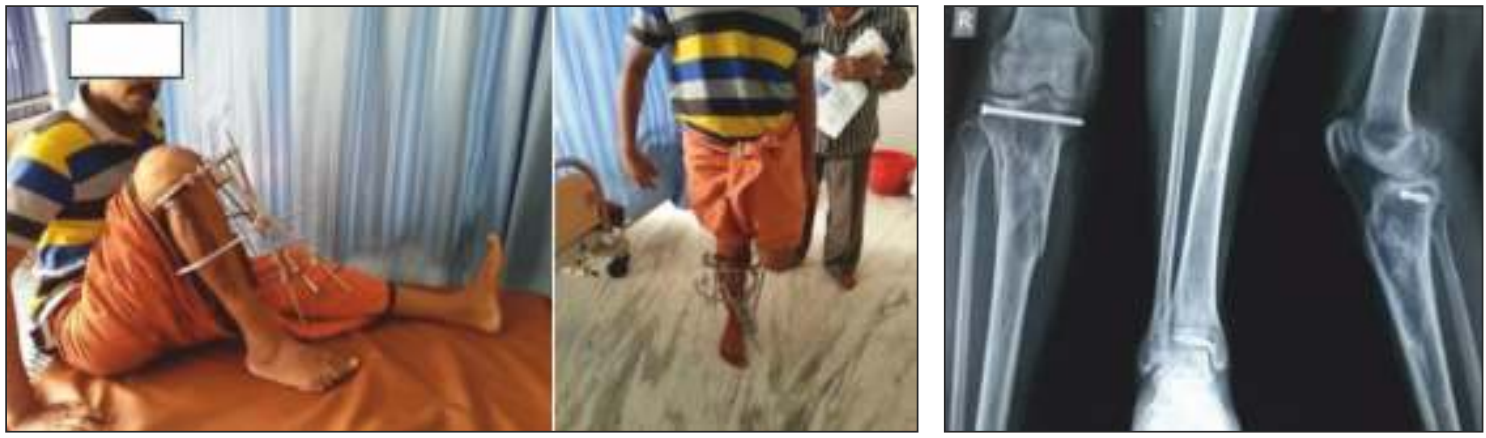

Fig. 19 : Final result

Definitive conclusions for the controversies in compartment syndrome

Compartment syndrome is an acute emergency. Clinical signs of 5 Ps are paramount.when there is suspicion, be positive. Measure the perfusion pressure and act if intra compartment pressure above $30 \mathrm{~mm}$ (Mubarak et al) or pressure gradient within $30 \mathrm{~mm}$ of diastolic pressure (McQueen et al).
Fasciotomy is reliable, safe and effective provided done on time, preferably within 8 hours of onset of symptoms. All the compartments are to be released. Temporary ex-fix followed by definitive fixation is safe if the mentioned principles are adhered to. More than 12 hrs of the onset better to treat the residual problems 


\section{References}

1. RorabeckCH,Clarke KM., "The pathophysiology of the anterior tibial compartment syndrome: an experimental investigation," J Trauma.1978;18(5):299-304.

2 R. Volkmann, "The ischemic muscular paralysis and trauma, "Zentralblatt fur Chirurgie" , vol. 8, pp. 801-803, 1881.

3 McQueen MM,GasonP,Court-Brown CM., "Acute compartment syndrome. Who is at risk?,"JBJS(Br).2000;82B:200

4 Elliot KG,Johnstone AJ., "Diagnosing acute compartment syndrome,"JBJS(Br).2003;85:625.

5 F. A. M atsen III, R. A. Winquist, and R. B. Krugmire J r., "Diagnosis and management of compartmental syndromes," Journal of Bone and Joint Surgery-SeriesA, vol. 62, no. 2, pp. 286-291, 1980.

6 Hammerberg EM,Whtesdes TE Jr,Seiler JG, "The reliability of measurement of tissue pressure in compartment syndrome,"JOrthop Trauma.2012;26:24.

7 Reneman RS,Slaaf DW,Lindbom L, "M uscle blood flow disturbances produced by simultaneously elevated venous and total muscle tissue pressure,"M icrovasc Res. 1980;20:307.

8 McQueen MM,Court-Brown CM., "Compartment monitoring in tibialfractures,"JBJS(Br).1996;78:99.

9 McQueen MM, Gaston P, Court-Brown CM: Acute compartment syndrome: who is at risk? J Bone Joint Surg Br. 2000; 82:200-3.

10 Uliasz, A., Ishida, J.T., Fleming, J.K. et al, Comparing the methods of measuring compartment pressures in acute compartment syndrome. AmJ Emerg Med. 2003;21:143.

11 Gelberman R. H., Garfin S. R., Hergenroeder P. T., M ubarak S. . ., M enon J. Compartment syndromes of the forearm: diagnosis and treatment. Clinical Orthopaedics and Related Research. 1981;161:252-261.

12 G. J. Mar, M. J. Barrington and B. R. M cGuirk, "Acute Compartment Syndrome of the Lower Limb and the Effect of Postoperative Analgesia on Diagnosis," British Journal of Anaesthesia, Vol. 102, No. 1, 2009, pp. 3-11.

13 Rorabeck $\mathrm{CH}$, "The treatment of compartment syndromes of the leg,"JBJS(Br).1984;66:93-97.

14 Mubarak SI,Owen CA, "Double incision fasciotomy of the leg for decompression in compartment syndrome,"JBJS(Am).1977;59:184187.

15 Kanlic EM ,Pinski SE, Verwiebe EG, Saller J, Smith WR, "Acute morbidity and complications of thigh compartment syndrome":a report of 26 cases, "Patient Safety in Surgery.2010;4:13.

16 Egol KA, Ong CC, walsh IM et al. Early complications in proximal humerus fractures (OTA type II) treated with locked plates. J.Orthop. Trauma 2008-22(3) 159-164.
17 Jin Young GO, Yu-Sun M in, Tae-Du Jung. Delayed onset of Acute Limb Compartment Syndrome with Neuropathy after Venoarterial extracorporeal membrane oxygenation therapy. Ann Rehabil Med 2014 Aug; 38(4): 575-580.

18 John A. M cLaughlin, M elyssa M. Paulson, Ronald E. Rosenthal. Delayed onset of anterior tibial compartment syndrome in a patient receiving low-molecular-weight Heparin. As case Report. J. Bone Joint Surg. Am, 1998Dec; 80(12):1789-90.

19 Robert J. Gaines, Craif J, Randall, Kerri L. Browne, Donald R. Carr and Jerome G. Enad. Delayed presentation of Compartment Syndrome of the Proximal Lower Extremity after Low-energy trauma in patients taking Warfarin. Am J Orthop. 2008 December; 37(12): E201-E204

20 Nigel Tapiwa et al. Acute compartment syndrome of Limbs - current concepts and management. Open Orthop J. 2012; 6: 535-543.Brighton, UK

21 Saikia KC, Bhattacharya TD, Agarwala V. Anterior compartment pressure measurement in closed fractures of leg. Indian J Orthop 2008;42:217-21.

22 DK Meena et al. Results of Neurolysis in Established Upper Limb Volkmann's Ischemic Contracture Indian J Orthop 50 (6), 602-609. Nov-Dec 2016

23 Valliancourt C,Shrierl, Vandal A, Falk M, Rossignol M, Vernec A, Somogyi D, "Acute compartment syndrome: how long before muscle necrosis occurs?," CJEM .2004;6(3):147-54.

24 Mabvuure NT, Malahias M, Hindocha S, Khan W, Juma A, "Acute compartment syndrome of the limbs:Current concepts and management. Open Orthop J.2012;6:535-543.

25 Zwipp H, "Reconstructive surgery of sequalae of compartment syndrome of the leg and foot. Presentation of a new classification,"Unfallchrurg.2008;111(10):776-784.

26 Sheridan GW, M atsen FA 3rd. Fasciotomy in the treatment of the acute compartment syndrome. J Bone Joint Surg Am. 1976Jan;58(1):112-5.

27 Hak D. J., Lee M., Gotham D. R. Influence of prior fasciotomy on infection after open reduction and internal fixation of tibial plateau fractures. J Trauma, 2010:(69):886-8.

28 Bhargava $\mathrm{R}$ et al. Proximal Tibial fractures with impending Compartment Syndrome Original Article Indian Journal of Orthopaedics 2015 Vol. 49 p. 502-509

29 Cole PA, Zlowodzki M, Kregor PJ. Compartment pressures after submuscular fixation of proximal tibia fractures. Injury, 2003:(34 Suppl 1):A43-6

30 Personal communication with illustrations Dr. P.V Jayasankar, M edical Director, Sundaram Medical Foundation and Dr. Rangaraja Hospital, Chennai 